\title{
POU2F1 activity regulates HOXD10 and HOXD11 promoting a proliferative and invasive phenotype in Head and Neck cancer
}

\author{
Daniel J. Sharpe ${ }^{1}$, Katy S. Orr ${ }^{1}$, Michael Moran ${ }^{1}$, Sharon J. White ${ }^{2}$, Stephen \\ McQuaid ${ }^{3}$, Terence R. Lappin ${ }^{1}$, Alexander Thompson ${ }^{1}$ and Jacqueline A. James ${ }^{1,3}$ \\ ${ }^{1}$ Centre for Cancer Research and Cell Biology, Queen's University Belfast, Belfast \\ 2 Pathology Department, Ninewells Hospital \& Medical School, Dundee \\ 3 The Northern Ireland Molecular Pathology Laboratory, Centre for Cancer Research and Cell Biology, Queen's University \\ Belfast, Belfast and The Belfast Trust, Belfast City Hospital, Lisburn Road, Belfast
}

Correspondence to: Jacqueline A. James, email: j.james@qub.ac.uk

Keywords: Head and Neck cancer; HOXD10; HOXD1 1; POU2F1; Biomarker

Received: July 16, $2014 \quad$ Accepted: September 15, $2014 \quad$ Published: September 16, 2014

This is an open-access article distributed under the terms of the Creative Commons Attribution License, which permits unrestricted use, distribution, and reproduction in any medium, provided the original author and source are credited.

\section{ABSTRACT}

HOX genes are master regulators of organ morphogenesis and cell differentiation during embryonic development, and continue to be expressed throughout postnatal life. To test the hypothesis that HOX genes are dysregulated in head and neck squamous cell carcinoma (HNSCC) we defined their expression profile, and investigated the function, transcriptional regulation and clinical relevance of a subset of highly expressed HOXD genes.

Two HOXD genes, D10 and D11, showed strikingly high levels in HNSCC cell lines, patient tumor samples and publicly available datasets. Knockdown of HOXD10 in HNSCC cells caused decreased proliferation and invasion, whereas knockdown of HOXD11 reduced only invasion.

POU2F1 consensus sequences were identified in the 5' DNA of HOXD10 and D11. Knockdown of POU2F1 significantly reduced expression of HOXD1O and D11 and inhibited HNSCC proliferation. Luciferase reporter constructs of the HOXD10 and D11 promoters confirmed that POU2F1 consensus binding sites are required for optimal promoter activity.

Utilizing patient tumor samples a significant association was found between immunohistochemical staining of HOXD10 and both the overall and the diseasespecific survival, adding further support that HOXD10 is dysregulated in head and neck cancer. Additional studies are now warranted to fully evaluate HOXD10 as a prognostic tool in head and neck cancers.

\section{INTRODUCTION}

Head and Neck cancer encompasses a heterogeneous group of malignancies that can differ markedly in presentation, treatment and prognosis [1]. Approximately 95\% of these cancers are squamous cell carcinomas that affect the oral cavity, oropharynx, hypopharynx, nasopharynx and larynx [2]. Head and neck squamous cell carcinoma (HNSCC) accounts for approximately $2 \%$ of all malignancies worldwide [3]. Diagnosis of HNSCC is often made at an advanced stage, and despite improved therapeutic regimens over the past few decades, the 5 -year relative survival has shown only modest improvement [4]. A better understanding of the pathogenesis of HNSCC may provide useful insights for the development of novel therapeutic strategies.

The HOX gene network encodes a family of proteins which act as master regulators of developmental processes. Combinations of HOX genes specify the anterior-posterior axis and segment identity during early embryonic development, and postnatally $H O X$ genes continue to execute critical regulatory roles in many processes such as apoptosis, receptor signaling, motility and angiogenesis (reviewed by Shah and Sukumar [5]). Numerous observations of dysregulated HOX gene 
expression in solid tumors and leukemia [6] suggest that $H O X$ genes are important for both oncogenesis and tumor suppression, but their functional role in cancer onset and maintenance requires further investigation.

There have been relatively few reports of $H O X$ gene function in HNSCC, but $H O X$ gene expression profiles have been investigated in some related cancers. Takahashi and colleagues analyzed all 39 HOX genes by real time quantitative PCR in normal and neoplastic tissue and found altered expression of some genes in thyroid cancer cell lines [7]. Utilizing a similar approach Chen's group found dysregulated expression of $H O X$ genes in esophageal squamous cell carcinoma [8] and Hassan and colleagues found that $18 \mathrm{HOX}$ genes were significantly higher in oral squamous cell carcinoma than in normal mucosa cell lines [9]. The severely disordered expression affecting multiple $H O X$ genes found in these cancers suggests that the normal regulatory processes have become skewed, but to date few transcription factors regulating $H O X$ gene expression have been identified [10].

In the present study, we have defined the expression profile of all $39 \mathrm{HOX}$ genes in HNSCC cells, the majority of which are upregulated compared to normal oral keratinocytes (NOKs). A subset of highly expressed $H O X D$ genes was investigated further by functional knockdown studies and POU2F1 is identified as a transcriptional regulator of both $H O X D 10$ and $D 11$. Detailed examination of a cohort of patient biopsies $(n=120)$ highlights HOXD10 as a potential prognostic biomarker in HNSCC.

\section{RESULTS}

\section{Occurrence of $\mathrm{HOX}$ genes in HNSCC cell lines and clinical samples}

Comparative expression profiling by Q-PCR showed that 23 out of $39 \mathrm{HOX}$ genes were expressed significantly higher in HNSCCs $(n=4)$ compared with NOKs $(n=3)$ $(\mathrm{p}<0.05)$. A striking increase in the expression of four contiguous genes in the HOXD cluster (HOXD8-HOXD11) was evident in HNSCCs (Fig 1A and Supp Fig 1). HOXD
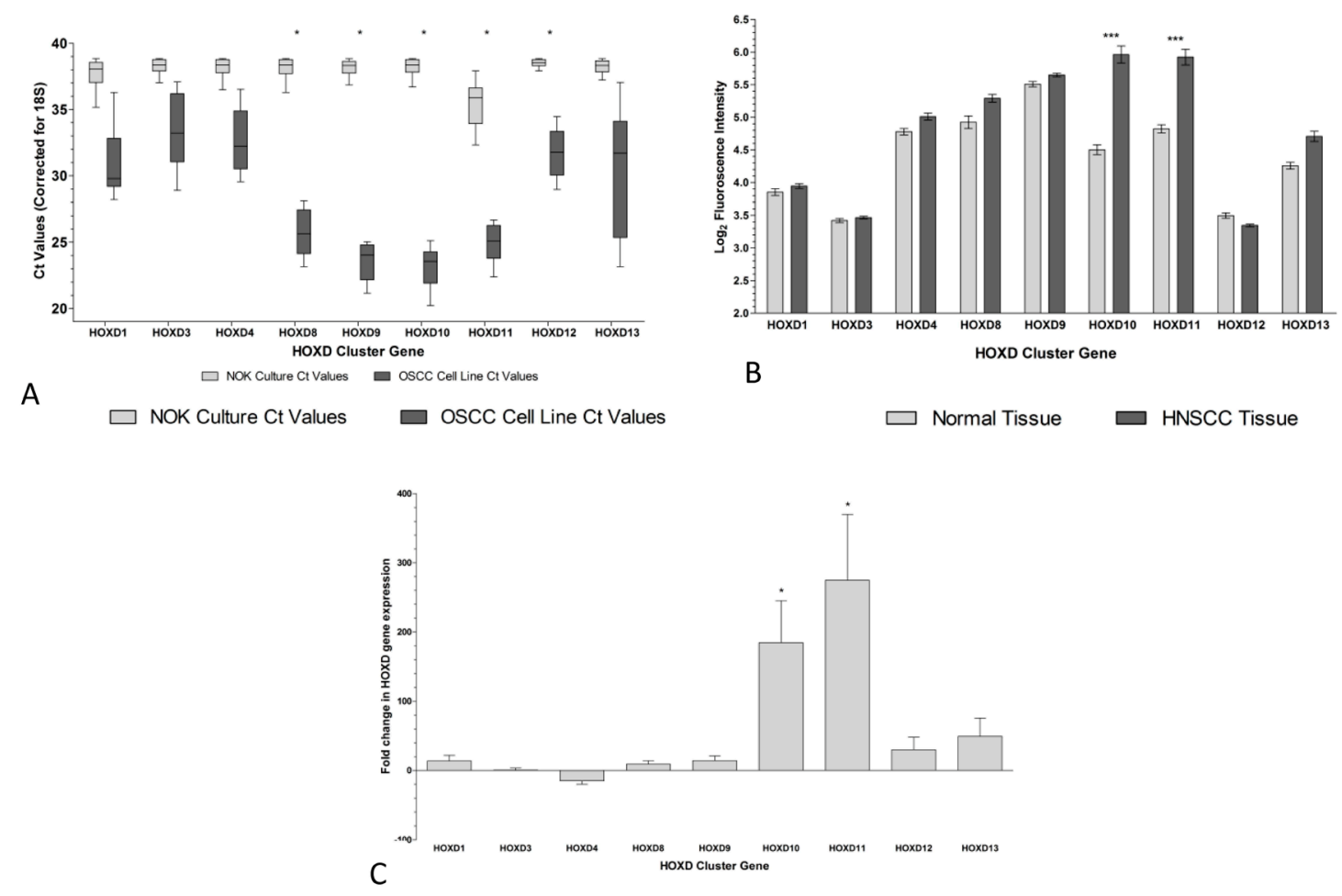

Figure 1: $H O X$ genes are highly expressed in Head and Neck squamous cell carcinoma (HNSCC) compared to normal oral keratinocytes (NOK) or control tissue. A. Total RNA was extracted from four HNSCC cell lines and three NOK cultures. The expression of each $H O X$ gene was analyzed in triplicate. Box plots indicating the range of expression of the HOXD cluster in NOKs $(\square)$, and HNSCCs ( ) are shown. Whiskers indicate minimum and maximum values; boxes indicate inter-quartile range, with the mean marked. Real-time Q-PCR values were corrected to $18 \mathrm{~S}$ ribosomal RNA levels. Statistical differences were detected by two-way ANOVA and consistently significant genes are indicated by *. B. Probe intensities of control and tumor tissue were extracted after normalization of expression files. Bars represent mean probe intensity level $( \pm$ SEM). Significantly different expression was detected by one-way ANOVA, $* * * \mathrm{p}<0.001$. C. RNA was extracted from eight tumor tissue samples and patient matched control tissue. Expression of the HOXD cluster was analyzed by real-time quantitative PCR and the fold difference in expression between matched tumor and control tissue calculated. The mean fold differences $( \pm$ SEM) are shown and statistical significances were detected by one-sample t-test and are indicated by * $(p<0.05)$. 
cluster expression was further analyzed in RNA extracted from a cohort of macro-dissected fresh-frozen tissue samples by Q-PCR. HOXD10 was 185 -fold and HOXD11 was 275-fold higher in HNSCC tissue compared to the patient-matched control tissue, but none of the other $H O X D$ genes were significantly different (Fig 1B).

$H O X$ expression was also evaluated in a publicly available microarray dataset comprising $60 \mathrm{HNSCC}$ and 12 control tissue samples. Twelve $H O X$ genes showed significantly increased expression in the HNSCC samples, including HOXD10 and D11 (Fig 1C and Supp Fig 2), supporting the cell line data.

Thus HOXD10 and D11, consistently highly expressed in HNSCC cell lines, macro-dissected tumor tissue samples, and in publicly available tissue microarray data from patients with HNSCC, were selected as candidate genes for further study. At the protein level, HOXD10 was shown to be confined to the nucleus, as expected, and higher levels of nuclear HOXD10 were observed in all four HNSCC cell lines compared to the NOK cultures (Fig 2A). No antibody to HOXD11 of adequate specificity for western blotting was commercially available. Targeted knockdown of $H O X D 10$ or $H O X D 11$ was confirmed in $\mathrm{H} 357$ cells by Q-PCR (Fig 2B) and HOXD10 depletion was confirmed by western blot analysis (Fig 2C). A dramatic decline in the growth rate of H357 cells of approximately $40 \%$ was observed after siRNA knockdown of HOXD10 (Fig 2D) and significant growth inhibition $(\mathrm{p}<0.001)$ was further confirmed by crystal violet clonogenic assays compared to scrambled siRNA controls (Fig 2E, left panel). Targeted knockdown of HOXD11 did not result in significant growth inhibition as determined by the same assays (Fig 2D and Fig 2E, right panel). At the cellular level, a decrease in the rate of cell division in HOXD10 depleted H357 cells with an increase in $\mathrm{G}_{0}$ phase cells and concomitant decrease in the $\mathrm{S}$ phase population was demonstrated using propidium iodide staining (Fig 2F). This observed growth reduction does not appear to be due to an increase in apoptosis (Fig 2G). At the functional level, knockdown of either HOXD10 or HOXD11 (alone) did not affect H357 cell migration (Fig 2H), however, invasion of the H357 cells through Matrigel was significantly reduced by knockdown of either HOXD10 or HOXD11 (Fig 2I). Taken together these results indicate that HOXD10 and, to a lesser extent HOXD11, promote the malignant phenotype of HNSCC.

\section{Investigation of potential transcriptional regulators of $\mathrm{HOXD} 10$ and $\mathrm{HOX} D 11$}

To identify potential regulators of $H O X D 10$ and $H O X D 11$ common to both genes, we searched for transcription factor binding sites (TFBSs) shared by their promoters. We examined $2.5 \mathrm{~kb}$ surrounding the start site of all of the HOXD cluster genes using MATCH, a weight matrix-based tool for searching putative transcription factor binding sites in DNA [11], with a cut-off to minimize false positive results. The consensus sequences of only 2 transcription factors, namely CUTL1 and POU2F1, were present in the $5^{\prime}$ DNA region of both $H O X D 10$ and $H O X D 11$. POU2F1 consensus sequences were also identified in the $5^{\prime}$ DNA region of $H O X D 8$ and $H O X D 9$ which, like $H O X D 10$ and $H O X D 11$, were highly expressed in the HNSCC cell lines.

The expression of $P O U 2 F 1$ was assessed in the four HNSCC and three NOK cell lines, in patient tissues, and in publicly available microarray datasets. In HNSCC cell lines POU2F1 was 7.5-fold the level in NOKs $(\mathrm{p}<0.05)$, as determined by Q-PCR (Fig 3A). In patient tumor tissue samples $(\mathrm{n}=8)$ the level of $P O U 2 F 1$ was higher by 5.3 -fold compared to matched control samples $(\mathrm{P}<0.05)$ by $\mathrm{Q}-\mathrm{PCR}$ (Fig 3B). The expression of POU $2 F 1$ was not significantly altered in HNSCC tissue compared to contralateral control tissue in the publicly available microarray datasets (data not shown).

To determine whether POU2F1 acts as a transcriptional regulator of $H O X D 10$ and $D 11$ genes, their expression was assessed in POU $2 F 1$ knockdown cells. Decreases in $H O X D 10$ and $D 11$ expression of 2- to 8-fold were observed with POU $2 F 1$ knockdown $(\mathrm{p}<0.01)$, but there was no change in HOXD1 level, which does not contain a POU2F1 consensus binding sequence (Fig 3C). The decrease in HOXD10 expression was confirmed by western blot, which showed a 2- to 5-fold decrease in HOXD10 protein after POU2F1 knockdown (Fig 3D).

Further proof of the regulation of $\mathrm{HOX} 10$ and $\mathrm{D} 11$ by POU2F1 was obtained from luciferase assays using the putative promoter regions containing the POU2F1 binding sequences. When $P O U 2 F 1$ levels were reduced by siRNA in H357 cells, both the HOXD10 and D11 promoter constructs showed significant decreases in activity of approximately 50\% (Fig 3E). Deletion of the POU2F1 binding site from the HOXD10 promoter luciferase construct significantly reduced the $H O X D 10$ promoter activity by $17 \%$. Further analysis of the HOXD10 5' DNA revealed a second, less conserved consensus binding site and mutation of this site further reduced the promoter activity by $24 \%$. Similarly, deletion of the POU2F 1 binding sequence in the $H O X D 11$ promoter significantly reduced the $H O X D 11$ promoter activity by $74 \%$ (Fig $3 \mathrm{~F})$. Additionally, ChIP assays confirm direct binding of POU2F1 to the promoter regions of HOXD10 and HOXD11 (Supp Fig 3). These data support the contention that POU2F1 is a transcriptional regulator of $H O X D 10$ and D11.

A significant decrease in cell growth was observed upon targeted POU $2 F 1$ knockdown after $48 \mathrm{hr}(\mathrm{p}<0.001)$. This effect was much greater with $P O U 2 F 1$ siRNA 2 than with siRNA 1 , equating to increases in doubling time of $116 \%$ and $30 \%$ respectively (Fig $4 \mathrm{~A}$ ), which was also reflected in a significant reduction (3- to 5-fold) in 


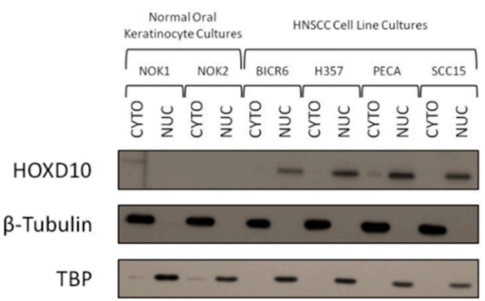

A

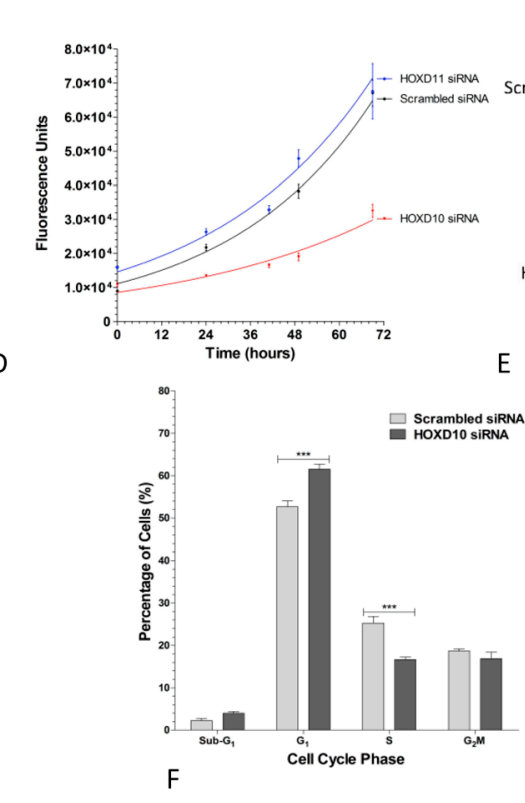

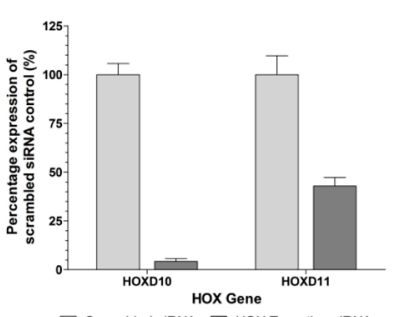

B $\square$ Scrambled siRNA $\square$ HOX Targeting siRNA

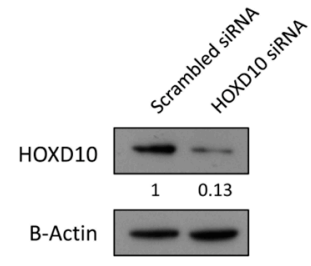

C

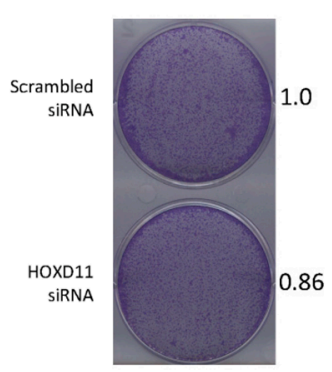

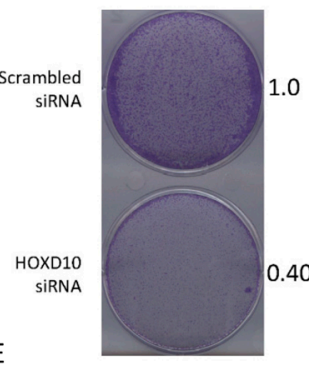
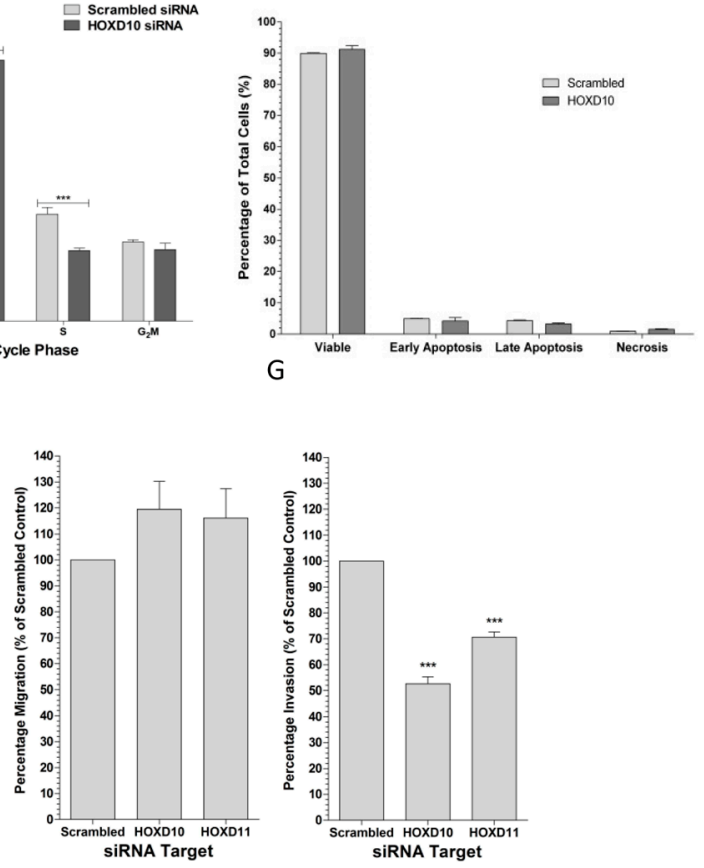

H

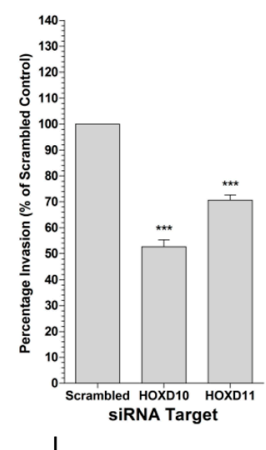

Figure 2 : HOXD10 and HOXD11 promote a proliferative and/or invasive phenotype in HNSCC. A. Western blot analysis of nuclear and cytoplasmic proteins extracted from HNSCC cell lines and NOK cultures. Appropriate fractionation of the proteins was confirmed by detection of $\beta$-tubulin (cytoplasmic protein) and TATA Binding Protein (TBP; nuclear protein). B. Q-PCR analysis confirming depletion of HOXD10 or HOXD11 expression in HNSCC cells transfected with HOXD10 or HOXD11 siRNA. C. Western blot analysis of HOXD10 siRNA transfected HNSCC cells confirming HOXD10 protein depletion. D. The growth of HNSCC cells transfected with scrambled, HOXD10 or HOXD11 specific siRNAs was assessed using CellTiter-Glo over a period of 70 hours. Graph represents the mean $( \pm \mathrm{SEM})$ of 3 independent experiments. E. Clonogenic growth assays of HNSCC cells transfected with scrambled, HOXD10 or HOXD11 specific siRNA. Values represent the mean relative OD540 nm adsorption of three independent experiments normalized to scrambled control F. Cell cycle quantification of HNSCC cells transfected with scrambled siRNA or HOXD10 targeting siRNA by flow cytometry. Statistical differences as determined by two-way ANOVA are indicated by $* * *(p<0.001)$. G. Apoptotic cell populations were detected in siRNA transfected HNSCC cells after 72 hours using annexin V/PI staining and flow cytometry. Graph represents mean apoptotic cell subpopulations as a percentage of total cells ( \pm SEM). H. Quantification of migration of HOX depleted HNSCC cells along a FCS gradient through a porous membrane measured after 24 hours using CellTiter-Glo. Graph represents mean percentage of migratory cells $( \pm$ SEM) normalized to input cell number expressed relative to scrambled siRNA control. I. Quantification of invasion of HOX depleted HNSCC cells along a FCS gradient through a Matrigel layer measured after 72 hours using CellTiter-Glo. Each assay was normalized to input cell number. Graph represents mean percentage of invasive cells $( \pm \mathrm{SEM})$ relative to scrambled siRNA control. Statistical differences as determined by one-way ANOVA are indicated by $* * *(\mathrm{p}<0.001)$. 

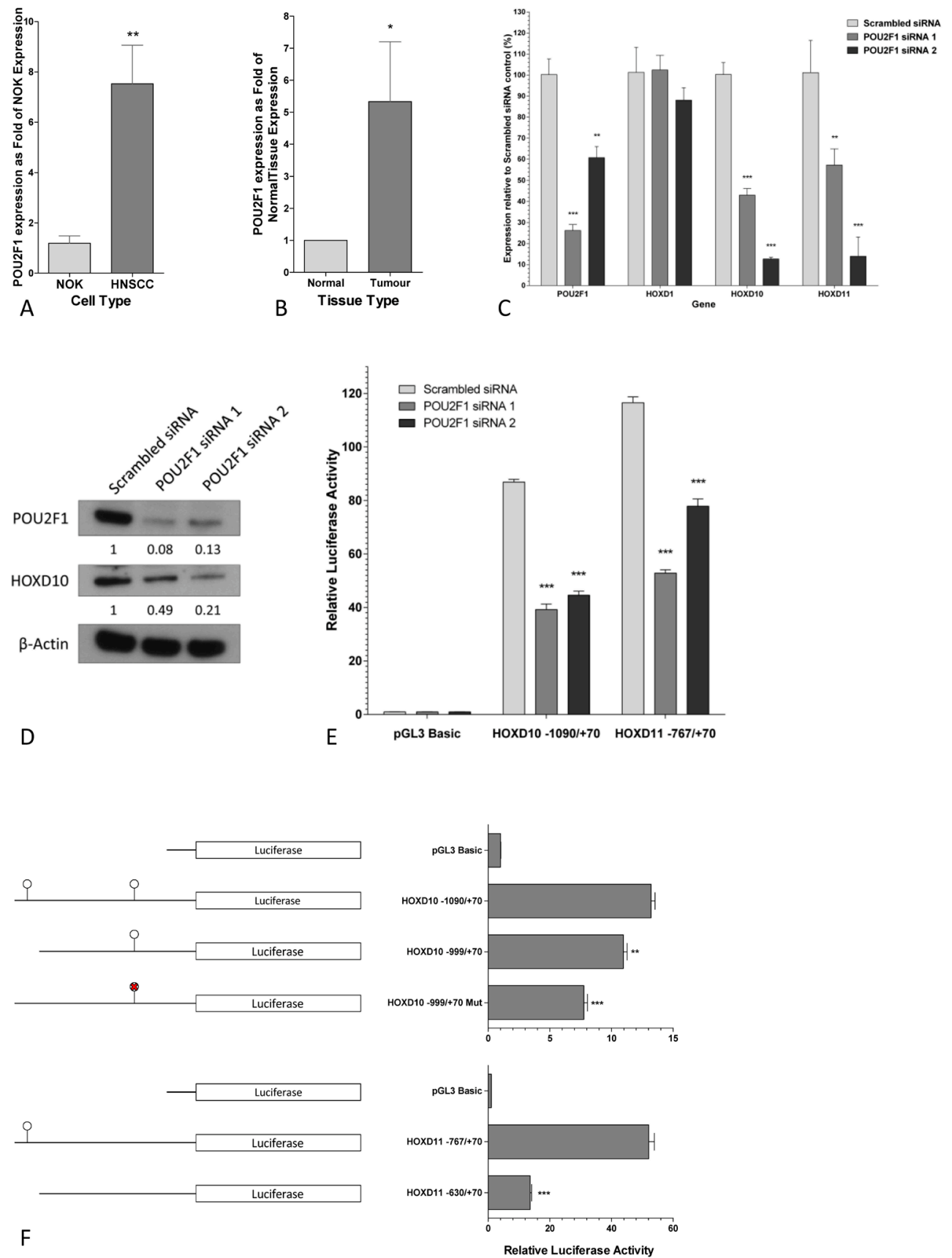

Figure 3 : POU2F1 positively regulates the transcription of HOXD10 and HOXD11. A. Q-PCR analysis of POU2F1 in HNSCC cell lines and NOK cultures. The expression of each gene was analyzed in three biological replicates. Graph represents mean fold differences in POU2F1 expression compared to NOK cultures and statistical differences as determined by t-test with Welch's correction are indicated by $* *(p<0.01)$. B. Q-PCR analysis of POU2F1 in HNSCC and normal tissues. Graph represents mean fold differences in POU2F1 expression compared to normal tissue and statistical differences as determined by t-test with Welch's correction are indicated by * $(\mathrm{p}<0.05)$. C. Q-PCR analysis of POU2F1 and HOXD gene expression in HNSCC cells transfected with scrambled siRNA or POU2F1 targeting siRNAs 72 hours post transfection. Graph represents mean gene expression levels as percentage of scrambled siRNA control and statistical differences as determined by two-way ANOVA are indicated by $* *(p<0.01)$ or $* * *(p<0.001)$. D. Western blot analysis of POU2F1 and HOXD10 expression in POU2F1 depleted HNSCC cells confirms POU2F1 protein depletion and effect on expression of HOXD10. $\beta$-Actin was used to confirm equal protein loading. E. Luciferase assays were performed using the proximal promoters of HOXD10 or HOXD11. HNSCC cells were transfected with scrambled siRNA or POU2F1 specific siRNAs and the luciferase activity of the HOXD10 or HOXD11 promoters assessed 72 hours post siRNA transfection. Graph represents the mean normalized luciferase activity $( \pm \mathrm{SEM})$ and statistical differences as determined by two-way ANOVA are indicated by $* * *(\mathrm{p}<0.001)$. F. Luciferase assays were performed using promoters of HOXD10 or HOXD11. POU2F1 consensus binding sites are indicated by 9 . POU2F1 consensus binding sites mutated by site-directed mutagenesis are indicated by $\$$. Graph represents the mean normalized luciferase activity $( \pm$ SEM) and statistical differences as determined by two-way ANOVA are indicated by $* *(\mathrm{p}<0.01)$ or $* * *(\mathrm{p}<0.001)$. 
clonogenic assay cell growth compared to scrambled siRNA controls (Fig 4B). As for HOXD10, POU2F1 siRNA 2 depleted $\mathrm{H} 357$ cells showed a significant increase in cells in $\mathrm{G}_{0}$ with a concomitant decrease in $\mathrm{S}$ phase, whereas siRNA 1 did not elicit any change (Fig 4C). A relatively minor, but significant, increase in the apoptotic cell population was also found with siRNA 2 (Fig 4D). No change in invasive capability was observed after siRNA knockdown of POU2F1 in H357 cells (Fig 4E).
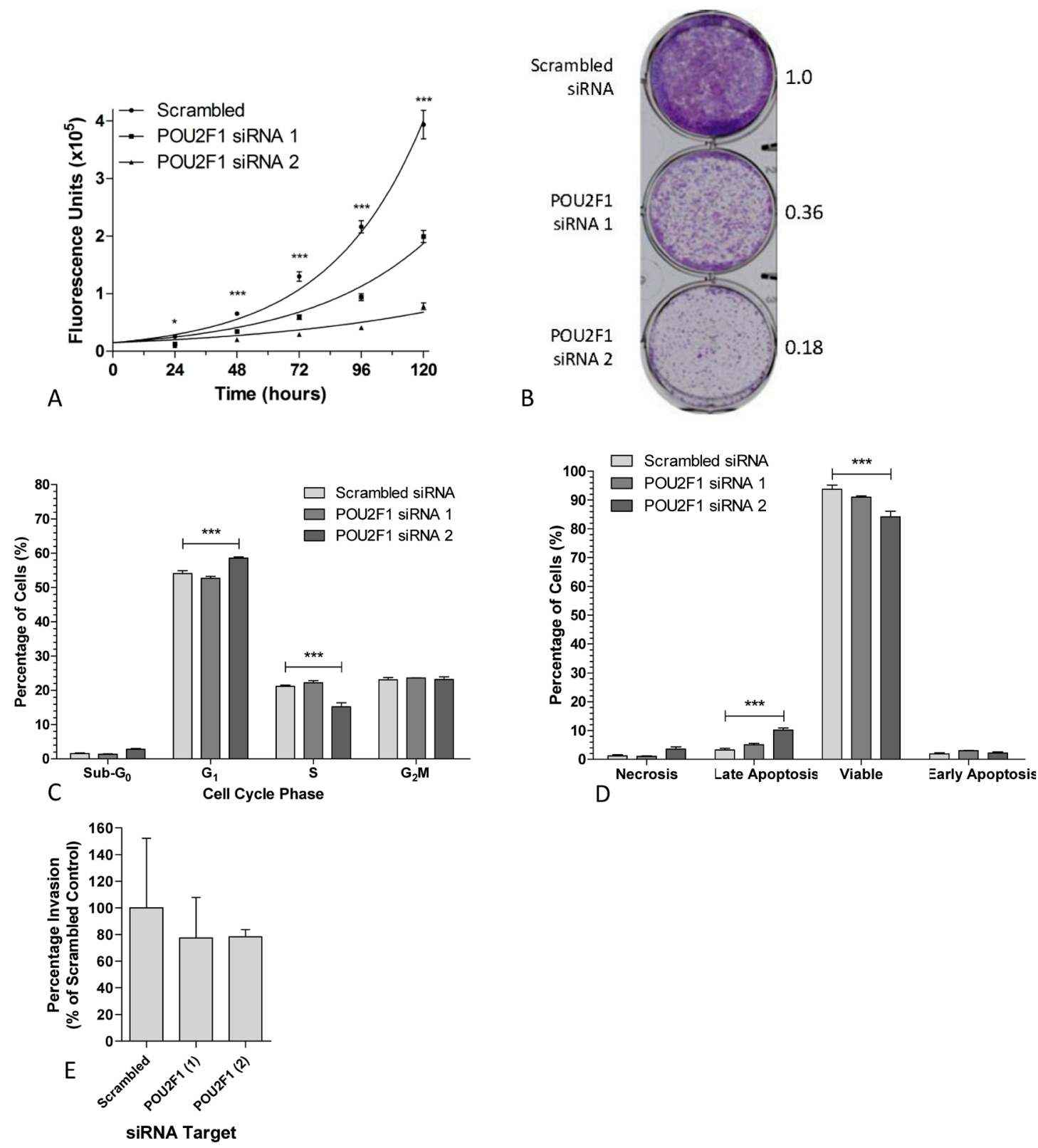

Figure 4 : POU2F1 promotes a proliferative phenotype in HNSCC. A. The growth of HNSCC cells transfected with scrambled, or POU2F1 specific siRNAs was assessed using CellTiter-Glo over a period of 120 hours. Graph represents the mean $( \pm$ SEM) of 3 independent experiments. Statistical differences as determined by two-way ANOVA are indicated by $*(\mathrm{p}<0.05)$ or $* * *(\mathrm{p}<0.001)$. B. Clonogenic growth assays of HNSCC cells transfected with scrambled or POU2F1 specific siRNAs. Values represent the mean relative OD540 nm adsorption of three independent experiments normalized to scrambled control. C. Cell cycle quantification of HNSCC cells transfected with scrambled siRNA or POU2F1 targeting siRNAs by flow cytometry. Statistical differences as determined by two-way ANOVA are indicated by $* * *(p<0.001)$. D. Apoptotic cell populations were detected in siRNA transfected HNSCC cells after 72 hours using annexin V/PI staining and flow cytometry. Graph represents mean apoptotic cell subpopulations as a percentage of total cells $( \pm$ $\mathrm{SEM}$ ). Statistical differences as determined by two-way ANOVA are indicated by $* * *(\mathrm{p}<0.001)$. E. Quantification of invasion of POU2F1 knockdown HNSCC cells along a FCS gradient through a Matrigel layer measured after 72 hours using CellTiter-Glo. Each assay was normalized to input cell number. Graph represents mean percentage of invasive cells $( \pm \mathrm{SEM})$ relative to scrambled siRNA control. 


\section{Immunohistochemical investigation of $\mathrm{HOXD10}$ in clinical samples}

To examine the potential clinical relevance of HOXD10 in HNSCC, a total of 120 patient samples in a TMA were immunohistochemically stained for HOXD10 protein expression. Six cases were lost to analysis due to insufficient clinical information or tumor representation in the TMA cores. Varying degrees of nuclear staining intensity were observed in HNSCC tissue of the 114 cases available for study (Fig 5A and Fig 5B). The associations between HOXD10 immunohistochemistry positivity and clinicopathological characteristics are summarized in Table 1. HOXD10 staining was significantly associated with increased smoking habit, and with more differentiated and earlier UICC stage tumors. To identify any association with overall or disease-specific survival, Kaplan-Meier survival curves were constructed using HOXD10 immunohistochemical staining to stratify patients (Fig 5C and Fig 5D). A significant difference in the survival curves of HOXD10 positive and HOXD10 negative patients was identified by the log-rank test for both overall $(p=0.00122)$ and disease-specific ( $p=0.00951)$ survival. Subsequent univariate Cox proportional hazards models identified significant associations between HOXD10 positivity and reduced overall survival $(\mathrm{p}=0.00172$; hazard ratio $=2.47)$ and disease-specific survival $(\mathrm{p}=0.0121$; hazard ratio $=2.48$ ), as shown in Table 2 . HOXD10 positivity was evaluated for independence from the described clinicopathological characteristics by generating a multivariate model with reverse-stepwise selection of variables. The variables included in the final multivariate models were: HOXD10 positivity, patient age, tumor site and tumor stage. The UICC stage of the disease was also included in the disease-specific survival model (Table 3; Supp Table 1). The association between HOXD10 and overall or disease-specific survival remained independently significant in this model with adjusted hazard ratios of $2.23(\mathrm{p}=0.00916)$ and 2.62. $(\mathrm{p}=0.0151)$ respectively. These data suggest that HOXD10 has a potential role in the prognosis of aggressive HNSCCs and warrants further study as a prognostic tool, independent of the established clinicopathological variables in head and neck cancers.

\section{DISCUSSION}

Definition of the roles of specific $H O X$ genes in malignancy is complicated because of functional redundancy in this large family of genes, their transcriptional regulators remain largely unknown, and relatively few HOX target genes have been identified.

In the current study 25 of the $39 \mathrm{HOX}$ genes were consistently more highly expressed in HNSCC cell lines than in NOKs. A subset of genes of the HOXD cluster, HOXD8-HOXD11, showed strikingly high levels in

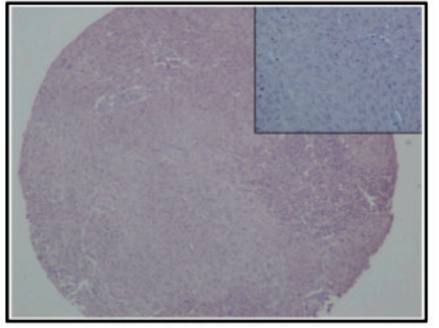

A

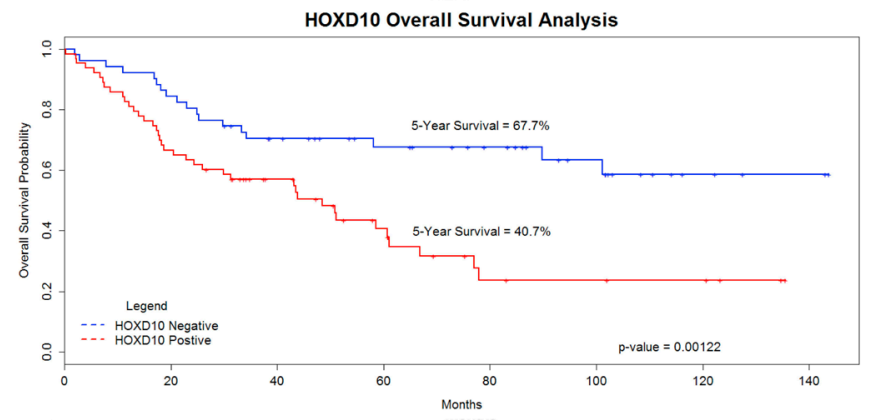

C

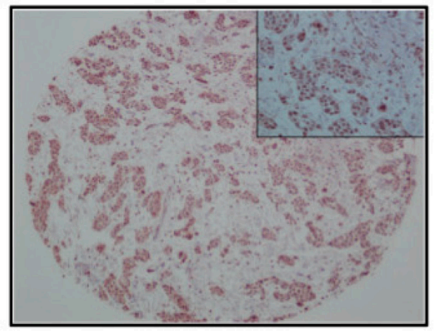

B

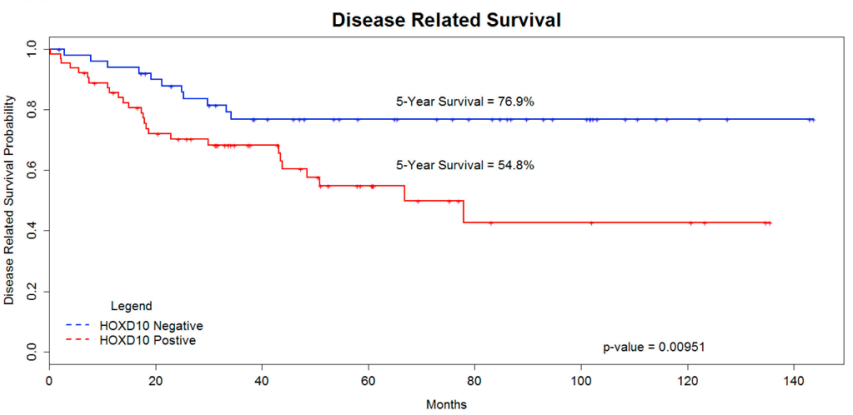

D

Figure 5: Immunochemical staining of HOXD10 in HNSCC associates with shortened patient survival. A. Representative sample of HOXD10 negative (IHC Quickscore $<50$ ) HNSCC patient tissue. Original magnification $\times 10$. Inset magnification $\mathrm{x} 40 \mathrm{~B}$. Representative samples of HOXD10 positive (IHC Quickscore>50) HNSCC patient tissue. HOXD10 immunoreactivity is largely confined to the nucleus. Original magnification $\times 10$. Inset magnification $\times 40 \mathrm{C}$. Kaplan-Meier analysis performed using overall survival statistics and HOXD10 immunoreactivity. High HOXD10 expression significantly associated with poor prognosis by the log-rank test (p-value $=0.00122$ ). D. Kaplan-Meier analysis performed using disease related survival statistics and HOXD10 immunoreactivity. High HOXD10 expression significantly associated with poor prognosis by the log-rank test ( $\mathrm{p}$-value $=0.00951$ ). 
Table 1: Clinicopathological correlations of HNSCC TMA patients with HOXD10 immunochemical staining. Correlations between clinicopathological features and HOXD10 immunostaining were assessed by Fisher's Exact Test.

\begin{tabular}{|c|c|c|c|c|}
\hline Parameter & \begin{tabular}{|l} 
Patients \\
N (\%)
\end{tabular} & $\begin{array}{l}\text { HOXD10 } \\
\text { Negative } \\
\text { N }(\%)\end{array}$ & $\begin{array}{l}\text { HOXD10 } \\
\text { Positive } \\
\text { N (\%) }\end{array}$ & $\begin{array}{l}\text { Fisher's Exact } \\
\text { Test } \\
\text { p-value }\end{array}$ \\
\hline $\begin{array}{l}\text { Age } \\
<57 \text { years } \\
\geq 57 \text { years } \\
\text { N/A }\end{array}$ & $\begin{array}{l}59(51.3) \\
55(47.8) \\
1(0.9)\end{array}$ & $\begin{array}{l}30(58.8) \\
21(41.2) \\
0(0)\end{array}$ & $\begin{array}{l}29(46.0) \\
33(52.4) \\
1(1.6)\end{array}$ & 0.2567 \\
\hline $\begin{array}{l}\text { Gender } \\
\text { Male } \\
\text { Female }\end{array}$ & $\begin{array}{l}85(73.9) \\
30(26.1)\end{array}$ & $\begin{array}{l}38(74.5) \\
13(25.5)\end{array}$ & $\begin{array}{l}46(73.0) \\
17(27.0)\end{array}$ & 1.0000 \\
\hline $\begin{array}{l}\text { Smoking } \\
\text { Non-Smoker } \\
\text { Light Smoker } \\
\text { Moderate Smoker } \\
\text { Heavy Smoker } \\
\text { N/A } \\
\end{array}$ & $\begin{array}{l}19(16.5) \\
8(7.0) \\
41(35.7) \\
27(23.5) \\
20(17.4) \\
\end{array}$ & $\begin{array}{l}13(25.5) \\
5(9.8) \\
12(23.5) \\
8(15.7) \\
13(25.5) \\
\end{array}$ & $\begin{array}{l}6(9.5) \\
3(4.8) \\
28(44.4) \\
19(30.2) \\
7(11.1) \\
\end{array}$ & 0.0121 \\
\hline $\begin{array}{l}\text { Alcohol } \\
\text { No Alcohol } \\
\text { Light Alcohol } \\
\text { Moderate Alcohol } \\
\text { Heavy Alcohol } \\
\text { N/A } \\
\end{array}$ & $\begin{array}{l}3(2.6) \\
21(18.3) \\
21(18.3) \\
30(26.1) \\
40(34.8) \\
\end{array}$ & $\begin{array}{l}1(2.0) \\
11(21.6) \\
7(13.7) \\
9(17.6) \\
23(45.1)\end{array}$ & $\begin{array}{l}2(3.2) \\
9(14.3) \\
14(22.2) \\
21(33.3) \\
17(27.0) \\
\end{array}$ & 0.2972 \\
\hline $\begin{array}{l}\text { Tumour Site } \\
\text { Base of Tongue } \\
\text { Oropharynx and Pharynx } \\
\text { Retromolar Trigone } \\
\text { Soft Palate } \\
\text { Tonsil }\end{array}$ & $\begin{array}{l}18(15.7) \\
14(12.2) \\
13(11.3) \\
9(7.8) \\
61(53.0) \\
\end{array}$ & $\begin{array}{l}7(13.7) \\
5(9.8) \\
2(3.9) \\
1(2.0) \\
36(70.6) \\
\end{array}$ & $\begin{array}{l}10(15.9) \\
9(14.3) \\
11(17.5) \\
8(12.7) \\
25(39.7) \\
\end{array}$ & 0.0057 \\
\hline $\begin{array}{l}\text { Ki67 positive } \\
<35 \% \\
\geq 35 \% \\
\end{array}$ & $\begin{array}{l}59(51.3) \\
56(48.7) \\
\end{array}$ & $\begin{array}{l}25(49.0) \\
26(51.0)\end{array}$ & $\begin{array}{l}33(52.4) \\
30(47.6)\end{array}$ & 0.8507 \\
\hline $\begin{array}{l}\text { Differentiation } \\
\text { Well/Moderately Differentiated } \\
\text { Poorly Differentiated } \\
\text { Undifferentiated/Anaplastic } \\
\text { N/A }\end{array}$ & $\begin{array}{l}77(67.0) \\
33(28.7) \\
0(0) \\
5(4.3) \\
\end{array}$ & $\begin{array}{l}27(52.9) \\
23(45.1) \\
0(0) \\
1(2.0) \\
\end{array}$ & $\begin{array}{l}49(77.8) \\
10(15.9) \\
0(0) \\
4(6.3) \\
\end{array}$ & 0.0015 \\
\hline $\begin{array}{l}\text { T Stage } \\
\text { Stage I } \\
\text { Stage II } \\
\text { Stage III } \\
\text { Stage IV } \\
\text { N/A } \\
\end{array}$ & $\begin{array}{l}30(26.1) \\
62(53.9) \\
14(12.2) \\
7(6.1) \\
2(1.7) \\
\end{array}$ & $\begin{array}{l}11(21.6) \\
30(58.8) \\
6(11.8) \\
3(5.9) \\
1(2.0) \\
\end{array}$ & $\begin{array}{l}18(28.6) \\
32(50.8) \\
8(12.7) \\
4(6.3) \\
1(1.6) \\
\end{array}$ & 0.8226 \\
\hline $\begin{array}{l}\text { UICC Stage } \\
\text { Stage I } \\
\text { Stage II } \\
\text { Stage III } \\
\text { Stage IV } \\
\text { N/A } \\
\end{array}$ & $\begin{array}{l}14(12.2) \\
15(13.0) \\
25(21.7) \\
58(50.4) \\
3(2.6) \\
\end{array}$ & $\begin{array}{l}2(3.9) \\
5(9.8) \\
11(21.6) \\
32(62.7) \\
1(2.0)\end{array}$ & $\begin{array}{l}11(17.5) \\
10(15.9) \\
14(22.2) \\
26(41.3) \\
2(3.2)\end{array}$ & 0.0472 \\
\hline
\end{tabular}

Table 2: Univariate Cox hazards associated with HOXD10 immuno-positivity and overall or disease-specific survival.

The correlations between patient characteristics including HOXD10 positivity and survival were assessed using Cox regression analysis.

\begin{tabular}{|c|c|c|}
\hline Parameter & 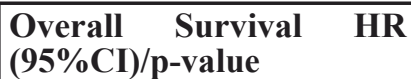 & $\begin{array}{l}\text { Disease Related Survival } \\
\text { HR }(95 \% \text { CI }) / p-v a l u e\end{array}$ \\
\hline $\begin{array}{l}\text { HOXD10 } \\
\text { Negative } \\
\text { Positive }\end{array}$ & $\begin{array}{l}\text { REFERENCE } \\
2.47(1.40-4.36) / 1.12 \times 10^{-3}\end{array}$ & $\begin{array}{l}\text { REFERENCE } \\
2.48(1.22-5.06) / 1.21 \times 10^{-2}\end{array}$ \\
\hline
\end{tabular}


Table 3 : Multivariate Cox hazard models associated with overall or disease-specific survival.

Multivariate Cox models were generated using reverse-stepwise regression to select the independent prognostic variables for HNSCC survival in this patient cohort. The variables included in the final multivariate models were: HOXD10 Immunohistochemical positivity, patient age, tumor site and tumor stage. The UICC stage of the disease was also included in the disease-specific survival model

\begin{tabular}{|c|c|c|}
\hline Parameter & $\begin{array}{|lc|}\text { Overall Survival } & \text { HR } \\
(95 \% \text { CI }) / p \text {-value }\end{array}$ & $\begin{array}{l}\text { Disease Related Survival } \\
\text { HR }(95 \% \mathrm{CI}) / \mathrm{p} \text {-value }\end{array}$ \\
\hline $\begin{array}{l}\text { HOXD10 } \\
\text { Negative } \\
\text { Positive }\end{array}$ & $\begin{array}{l}\text { REFERENCE } \\
2.23(1.22-4.09) / 9.16 \times 10^{-3}\end{array}$ & $\begin{array}{l}\text { REFERENCE } \\
2.62(1.20-5.70) / 1.51 \times 10^{-2}\end{array}$ \\
\hline $\begin{array}{l}\text { Age } \\
<57 \text { years } \\
\geq 57 \text { years }\end{array}$ & $\begin{array}{l}\text { REFERENCE } \\
2.49(1.43-4.33) / 1.28 \times 10^{-3}\end{array}$ & $\begin{array}{l}\text { REFERENCE } \\
2.62(1.26-5.43) / 9.86 \times 10^{-3}\end{array}$ \\
\hline $\begin{array}{l}\text { Tumour Site } \\
\text { Base of Tongue } \\
\text { Oropharynx and Pharynx } \\
\text { Retromolar Trigone } \\
\text { Soft Palate } \\
\text { Tonsil }\end{array}$ & p-value 0.41 & p-value 0.011 \\
\hline $\begin{array}{l}\text { T Stage } \\
\text { Stage I } \\
\text { Stage II } \\
\text { Stage III } \\
\text { Stage IV }\end{array}$ & $\begin{array}{l}\text { REFERENCE } \\
1.28(0.64-2.56) / 0.49 \\
2.36(0.91-6.08) / 0.08 \\
8.71(3.22-23.55) / 1.97 \times 10^{-5}\end{array}$ & $\begin{array}{l}\text { REFERENCE } \\
1.43(0.31-6.62) / 0.65 \\
4.99(0.98-25.3) / 0.05 \\
8.06(1.44-45.3) / 0.02 \\
\end{array}$ \\
\hline $\begin{array}{l}\text { UICC Stage } \\
\text { Stage I } \\
\text { Stage II } \\
\text { Stage III } \\
\text { Stage IV }\end{array}$ & - & $\begin{array}{l}\text { REFERENCE } \\
0.51(0.06-4.28) / 0.53 \\
0.58(0.09-3.82) / 0.57 \\
1.74(0.29-10.62) / 0.55\end{array}$ \\
\hline
\end{tabular}

HNSCCs compared to the flanking genes in the cluster, and all of the $H O X$ genes expressed in the non-malignant cells. Similarly HOXD10 and D11 in HNSCC tissue showed increases of greater than two logarithms compared to patient-matched control tissue. The increases in $H O X$ expression in HNSCC reflect the results of previous studies of oral squamous carcinoma, esophageal squamous cell carcinoma and thyroid cancer cell lines. In particular HOXD10 expression was higher in all three studies [7-9] and $H O X D 11$ was elevated in two of them $[7,9]$.

In functional studies knockdown of HOXD10 caused decreased proliferation and invasion, whereas knockdown of HOXD11 reduced invasion but did not affect proliferation. Knockdown of $H O X D 8$ or $D 9$ had no effect on proliferation, invasion or migration. Knockdown of HOXD10 and D11, significantly slowed migration of HNSCC cells through Matrigel. Taken together with the expression data for HOXD10 and HOXD11 these results indicate the possibility that the two genes are coordinately regulated.

In order to identify potential regulators of $H O X D 10$ and $H O X D 11$ we initiated a search using bioinformatic techniques for transcription factor binding sites in the $5^{\prime}$ DNA region of the HOXD genes. Two consensus binding sequences, CUTL1 and POU2F1 were identified in the 5 ' DNA of both genes. Interestingly, POU2F1 consensus binding sites were also identified in the 5' DNA of $H O X D 8$ and $D 9$ which were also highly expressed in the HNSCC cell lines. We therefore focused on POU2F1 which belongs to the POU family of transcription factors that control gene expression through interaction with the octamer element 5'-ATGCAAAT-3' and related motifs.

We found that POU2F1 is highly expressed in HNSCC cell lines compared to NOKs, and in patient tumor samples compared to tissue-matched control samples. Knockdown of $P O U 2 F 1$ by siRNA caused significant reduction in expression of HOXD10 and HOXD11, but not $H O X D 1$, which does not contain a POU2F1 consensus binding sequence. Upon $P O U 2 F 1$ knockdown luciferase constructs of $H O X D 10$ and D11 showed significantly reduced activity in $\mathrm{H} 357$ cells. Reduced activity was also observed after deletion of the POU2F1 binding sites in these constructs. Knockdown of POU2F1 caused a decrease in the proliferation of HNSCC cells, similar to the effect of HOXD10 knockdown. However, a complete recapitulation of the HOXD10 knockdown phenotype was not observed, likely due to the large number of genes known to be regulated by POU2F1 [12-14]. To our knowledge these results indicate for the first time that POU2F1 is an upstream regulator of $H O X$ expression, and that it has a role in the development and progression of HNSCC. Among other tissue-specific genes regulated by 
POU2F1 are osteopontin [15], iNOS [16] and the caudal homeobox gene $C d x$-2, itself a transcriptional activator for a cohort of genes specifically expressed in pancreatic islets and intestinal cells and implicated in the prevention of the development of colorectal tumors [17].

In order to define the potential relevance of HOXD10 in patient survival and prognosis we used tissue microarrays in conjunction with immunohistochemical staining. We found a significant association between HOXD10 positivity and reduced overall and diseasespecific survival. This association remained significant after adjustment for other clinicopathological variables such as age, tumor stage, smoking and tobacco habit indicating HOXD10 expression is independent of such factors.

Overall our results suggest that HOXD10 and $H O X D 11$ act as oncogenes in oral cancer, whereas previous reports have indicated that they act as tumor suppressors. In gastric carcinoma HOXD10 is downregulated and its forced expression is associated with reduced proliferation, invasion, migration and tumor growth [18]. In glioma cells HOXD10 also appears to have a tumor suppressive function as judged by repression of the invasion-related MMP-14 and uPAR genes [19]. In breast carcinoma cell lines loss of HOXD10 expression occurs during malignant transformation and subsequent forced re-expression leads to a more organized, phenotypically 'normal' structure in three-dimensional culture [20]. Less is known about the functions of HOXD11 in cancer although it has been identified as a fusion partner with NUP98 in $\mathrm{t}(2 ; 11)$ (q31;p15) acute myeloid leukemia [21]. There are few examples of therapeutic agents targeting either $H O X$ or $P O U$ proteins. Several studies using a $H O X-P B X$ binding inhibitor peptide have shown efficacy at inducing apoptosis in breast, prostate, melanoma and ovarian cancer cells during in vitro studies [22-25]. However, the efficacy of the HOX-PBX binding inhibitor peptide in head and neck cancer has yet to be assessed.

In conclusion, the strikingly high relative expression of HOXD10 and D11 in HNSCC cell lines, tumor tissue samples, and HOXD10 in the tissue microarray data, combined with the loss of function associated with their targeted knockdown argue for their role as oncogenes in the pathogenesis of HNSCC. Additional studies are warranted to fully evaluate the potential of HOXD10 as a target or prognostic tool in head and neck cancers.

\section{MATERIALS AND METHODS}

\section{Cell culture}

Four HNSCC cell lines were studied (i) H357 (derived from tongue, and received from Professor S. Prime, University of Bristol), (ii) BICR6 (derived from the pharynx, received from Professor K. Parkinson, University of London), (iii) PE/CA and (iv) SCC15 (both derived from tongue and purchased from ATCC). The NOK cultures, which were used between passage 2 and 7, were a gift from Professor C. Irwin, Queen's University Belfast who established the cultures from outgrowths of mucosal samples independently of fibroblast feeder cells (Ethics Ref: ORECNI 06/NIR01/90). The HNSCCs were normally maintained in keratinocyte growth medium (KGM; Invitrogen, Paisley, UK) [26] then switched to NOK media (Epilife supplemented with Human Keratinocyte Growth Supplement; both Invitrogen) prior to experimentation to standardize culture conditions.

\section{cDNA synthesis and quantitative PCR}

Total RNA was isolated from cultured cells using TRIzol (Invitrogen) according to the manufacturer's instructions. RNA from fresh frozen samples of matched control and tumor tissues from patients with $\operatorname{HNSCC}(n=8)$ were obtained from the Tayside Tissue Bank (Ethics Ref: TR000105 and TR000114). DNase I (Invitrogen) treated RNA $(5 \mu \mathrm{g})$ was reverse transcribed using M-MLV reverse transcriptase (Invitrogen) according to the manufacturer's instructions. Reactions were performed in a final volume of $20 \mu 1$.

Quantitative real-time RT-PCR (Q-PCR) was performed using TaqMan ${ }^{\mathrm{TM}}$ probe-based (Applied Biosystems, Foster City, California) chemistry on the Applied Biosystems 7500 Real Time PCR system to analyze the expression of each $H O X$ gene and $P O U 2 F 1$. $18 S$ ribosomal RNA expression was used as an internal standard for normalization. All Q-PCR reactions were performed under the following conditions: $50^{\circ} \mathrm{C}$ for $2 \mathrm{~min}$, $95^{\circ} \mathrm{C}$ for $10 \mathrm{~min}$ and 40 cycles of $95^{\circ} \mathrm{C}$ for $15 \mathrm{sec}, 60^{\circ} \mathrm{C}$ for $1 \mathrm{~min}$. The fluorescence was measured during the $60^{\circ} \mathrm{C}$ step. Primer and probe sequences for each gene target are available on request.

\section{Western blot}

Nuclear and cytoplasmic protein was extracted from cells by suspension in a solution of Buffer A containing $10 \mathrm{mM}$ HEPES pH 7.4, $1.5 \mathrm{mM} \mathrm{MgCl}_{2}, 10 \mathrm{mM} \mathrm{NaCl}$, $0.1 \% \mathrm{NP}-40$ and a cocktail of protease inhibitors (Complete Mini Cocktail, Roche Diagnostics Ltd, Lewes, UK). The cells were lysed on ice for $10 \mathrm{~min}$ after which they were passed through a 21 gauge needle to ensure complete plasma membrane lysis. Nuclei were pelleted by centrifugation $\left(12,000 \mathrm{x} \mathrm{g}\right.$ at $4^{\circ} \mathrm{C}$ for $2 \mathrm{~min}$ ) and the supernatant containing cytoplasmic protein was retained. Nuclei were washed in a solution of Buffer A (as specified above). The nuclei were lysed for 10 min on ice in Buffer A and sonicated for $30 \mathrm{sec}$ to completely disrupt the nuclear membrane. Remaining cell debris was pelleted 
by centrifugation and the supernatant containing nuclear protein retained. Total protein content was determined by the Bradford protein method using the BCA protein assay kit (Pierce, Cramlington, UK). Protein $(30 \mu \mathrm{g})$ was loaded onto a Tris-Glycine polyacrylamide gel (10\%) and subsequently transferred to a nitrocellulose membrane. The antibodies used for Western blotting were $\beta$-tubulin (Abcam 1:1000), HOXD10 (Biorbyt 1:200), POU2F1 (Abcam 1:1000) and TATA-BP (Abcam 1:1000).

\section{RNA Interference}

Knockdown of target $H O X$ genes or $P O U 2 F 1$ was performed using pooled siRNAs (HOXD8 and HOXD11, Dharmacon, Waltham, Massachusetts; HOXD9 and HOXD10, Qiagen, Crawley, UK, POU $2 F 1$ siRNA 1, 5'-CCAGCAGCUCACCUAUUAA-3' and POU $2 F 1$ siRNA 2, 5'-UGAUGCAGAGAACCUCUCA-3') or control (scrambled, Dharmacon). The HNSCC cell line H357 was seeded at $2 \times 10^{5}$ cells $/ \mathrm{cm}^{2}$, cultured for $24 \mathrm{hr}$ and transfected with the relevant siRNA (100 nM) using Lipofectamine 2000 transfection reagent (Invitrogen) in serum free media according to the manufacturer's instructions. Four hours post-transfection, 2 volumes of KGM containing $10 \%$ FCS were added. After a further 24 $\mathrm{hr}$ the transfection procedure was repeated.

\section{Cell Growth and Proliferation Assays}

Transfected cells were harvested after $48 \mathrm{hr}$, seeded at $1 \times 10^{3}$ cells/well in 96-well plates and allowed to attach for $16 \mathrm{hr}$. Cell number was assessed at intervals over a $70 \mathrm{hr}$ period using the CyQuant NF Cell Proliferation Kit (Invitrogen). Transfected H357 cells were trypsinized $48 \mathrm{hr}$ post-transfection and seeded in six-well plates at a density of $5 \times 10_{3}$ cells/well. The cells were allowed to grow for 3 days before staining with crystal violet. Crystal violet reabsorption was performed using $0.1 \mathrm{M}$ sodium citrate in $50 \%$ ethanol.

\section{Cell Migration and Invasion Assays}

Transfected cells were harvested after $48 \mathrm{hr}$ and migration or invasion assays were carried out using polycarbonate filters ( $8 \mathrm{~mm}$ pore size; Corning, Amsterdam, The Netherlands). Cells in serum-free media were plated into the upper chamber and allowed to migrate along a Fetal Calf Serum (FCS; Invitrogen) concentration gradient for $24 \mathrm{hr}$. The number of cells migrating to the lower chamber was assessed using the CyQuant Cell Proliferation Kit (Invitrogen). For invasion experiments, the polycarbonate filters were coated in Matrigel (100 $\mu \mathrm{g} / \mathrm{cm}^{2}$; BDBiosciences, Oxford, UK) $24 \mathrm{hr}$ prior to the assay, and incubated at room temperature overnight to dry under sterile conditions. The Matrigel was rehydrated with serum-free media $30 \mathrm{~min}$ before the addition of cells. Cells were allowed to invade through this layer towards FCS for $72 \mathrm{hr}$ prior to counting.

\section{Luciferase Assays}

HNSCC H357 cells were seeded into six-well plates at a density of $1 \times 10^{5}$ cells/well, transfected with control vector (pGL3-basic empty) or vectors containing approximately $1 \mathrm{~kb}$ of 5' DNA of $\mathrm{HOXD} 10$ or $\mathrm{HOXD} 11$ cloned upstream of firefly luciferase and co-transfected with renilla luciferase. The collection of samples and assays of luciferase activity were performed as previously described [27].

\section{ChIP assays}

ChIP assays were performed as detailed in supplemental methods. Briefly, formalin-fixed chromatin was isolated from H357 and BICR6 cells, sheared by sonication and immunoprecipitated with an anti-POU2F1 antibody. Isolated complexes were washed eight times with RIPA buffer and once with 1x TE before reversal of the DNA-protein crosslinking and DNA purification by QIAquick columns (Qiagen). DNA was subjected to Q-PCR analysis with gene promoter or non-specific region primers to evaluate promoter DNA enrichment.

\section{Tissue Microarrays and Immunohistochemistry}

Tissue microarray sections containing 120 cases of formalin fixed paraffin embedded (FFPE) HNSCC samples were obtained in triplicate from the Northern Ireland Biobank and used to assess the expression of HOXD10. Immunohistochemical (IHC) staining for HOXD10 was performed with a rabbit polyclonal antibody (Biorbyt, orb30360). An initial set of validation experiments was carried out using FFPE sections from human testes to optimize the staining on a fully automated Bond Max Immunostainer (Supplementary methods). Tumor cores (total in triplicate $n=360$ ) were scored by two observers ( $\mathrm{JJ}$ and SMcQ) blinded to the clinical outcomes of the patients. An independent training TMA with 33 HNSCCs (representing oral cavity, oropharyngeal and pharyngeal SCCs) was used initially to establish scoring concordance between observers. Homogeneous staining localized to the nucleus of the tumor cells was scored as positive. In cases of vesicular and open nuclei, the staining pattern was restricted to the nuclear membrane. The intensity of tumor cell staining was scored semi-quantitatively on a four point scale $(0$ - unstained at high power; 1 - weak; 2- moderate; 3 - strong). A Quickscore was determined for each tumor core and a series of normal tonsil control 
tissues (Supplementary methods), based on the product of the staining intensity and the proportion of epithelial cells stained positively. Quickscores determined for control tissues were all $<50$; therefore the score 50 was used to dichotomize the tumor cases into 'negative staining' which represented individual cases with an average Quickscore of less than 50, and 'positive staining' which represented individual cases with an average Quickscore of 50 or above. Clinical outcomes analyzed included diseasespecific survival and overall survival.

\section{Statistical Analysis}

For the in vitro tests containing more than two variables statistical analysis was performed by one-way or two-way analysis of variance (ANOVA) followed by Tukey's post-hoc multiple comparison tests. For tests containing only two variables the student's T-test with Welch's correction was used. Statistical significance was taken as $p<0.05$. The publically available microarray datasets were imported into R/Bioconductor (Version 3.0.0) and normalized by RMA using the package "affy". Statistical analysis was performed in Graphpad Prism 5.03 after extraction of normalized expression values. Immunohistochemistry data statistical analysis was performed in R/Bioconductor (Version 3.0.0) using the package "Survival". For each experiment the statistical tests were indicated in the Results sections. Fisher's exact tests were used to analyze associations between IHC scores and clinicopathological features. Statistical significance was calculated at a 95\% confidence level. Survival curves were constructed based on the Kaplan-Meier method and compared using Log-Rank tests. For univariate and multivariate survival analysis, the Cox proportional hazard model was employed. The multivariate model was built using a reverse step-wise regression.

\section{ACKNOWLEDGEMENTS}

This work was supported in part by development funds made available through the Belfast Cancer Research UK Centre and the Northern Ireland Cancer Research UK funded Experimental Cancer Medicine Centre (ECMC). The nucleic acids from human tissue samples were received from the Tayside Tissue Bank. Oral cancer cell lines were kindly donated by Professors Stephen Prime and Ken Parkinson. The tissue microarray sections were received from the Northern Ireland Biobank which is funded by Health and Social Care Research and Development Division of the Public Health Agency in Northern Ireland, the Friends of the Cancer Centre and Cancer Research UK. The construction of the tissue microarrays and the processing of the sections for immunohistochemical analysis were undertaken taken in the Northern Ireland Molecular Pathology Laboratory which has received support from Cancer Research UK through the ECMC, the Friends of the Cancer Centre and the Sean Crummey Foundation. DS was supported by a special research award from the School of Medicine, Dentistry and Biomedical Science, Queen's University Belfast.

\section{Conflict of Interest Statement}

The authors can confirm there is no conflict of interest associated with this work. None of the co-authors has information to disclose about financial interests, relationships or conflicts in the recent past or foreseeable future that is relevant to the topic of the manuscript.

\section{REFERENCES}

1. Argiris A, Karamouzis MV, Raben D and Ferris RL. Head and neck cancer. Lancet. 2008; 371(9625):1695-1709.

2. Skarsgard DP, Groome PA, Mackillop WJ, Zhou S, Rothwell D, Dixon PF, O’Sullivan B, Hall SF and Holowaty EJ. Cancers of the upper aerodigestive tract in Ontario, Canada, and the United States. Cancer. 2000; 88(7):17281738.

3. Ferlay J, Shin HR, Bray F, Forman D, Mathers C and Parkin DM. Estimates of worldwide burden of cancer in 2008: GLOBOCAN 2008. International journal of cancer Journal international du cancer. 2010; 127(12):2893-2917.

4. Howlader N, Noone A, Krapcho M, Neyman N, Aminou R, Altekruse S, Kosary C, Ruhl J, Tatalovich Z, Cho H, Mariotto A, Eisner M, Lewis D, Chen H, Feuer E and Cronin Ke. SEER Cancer Statistics Review, 1975-2009 (Vintage 2009 Populations), National Cancer Institute. Bethesda, MD.

5. Shah N and Sukumar S. The Hox genes and their roles in oncogenesis. Nature reviews Cancer. 2010; 10(5):361-371.

6. Grier DG, Thompson A, Kwasniewska A, McGonigle GJ, Halliday HL and Lappin TR. The pathophysiology of HOX genes and their role in cancer. The Journal of pathology. 2005; 205(2):154-171.

7. Takahashi O, Hamada J, Abe M, Hata S, Asano T, Takahashi Y, Tada M, Miyamoto M, Kondo S and Moriuchi T. Dysregulated expression of HOX and ParaHOX genes in human esophageal squamous cell carcinoma. Oncology reports. 2007; 17(4):753-760.

8. Chen KN, Gu ZD, Ke Y, Li JY, Shi XT and Xu GW. Expression of 11 HOX genes is deregulated in esophageal squamous cell carcinoma. Clinical cancer research : an official journal of the American Association for Cancer Research. 2005; 11(3):1044-1049.

9. Hassan NM, Hamada J, Murai T, Seino A, Takahashi Y, Tada M, Zhang X, Kashiwazaki H, Yamazaki Y, Inoue N and Moriuchi T. Aberrant expression of HOX genes in oral dysplasia and squamous cell carcinoma tissues. Oncology 
research. 2006; 16(5):217-224.

10. Soshnikova N, Dewaele R, Janvier P, Krumlauf R and Duboule D. Duplications of hox gene clusters and the emergence of vertebrates. Developmental biology. 2013; 378(2):194-199.

11. Kel AE, Gossling E, Reuter I, Cheremushkin E, KelMargoulis OV and Wingender E. MATCH: A tool for searching transcription factor binding sites in DNA sequences. Nucleic acids research. 2003; 31(13):3576-3579.

12. Zhao FQ, Zheng Y, Dong B and Oka T. Cloning, genomic organization, expression, and effect on beta-casein promoter activity of a novel isoform of the mouse Oct-1 transcription factor. Gene. 2004; 326:175-187.

13. Shakya A, Kang J, Chumley J, Williams MA and Tantin D. Octl is a switchable, bipotential stabilizer of repressed and inducible transcriptional states. The Journal of biological chemistry. 2011; 286(1):450-459.

14. Reymann S and Borlak J. Transcription profiling of lung adenocarcinomas of c-myc-transgenic mice: identification of the c-myc regulatory gene network. BMC systems biology. 2008; 2:46.

15. Wang D, Yamamoto S, Hijiya N, Benveniste EN and Gladson CL. Transcriptional regulation of the human osteopontin promoter: functional analysis and DNA-protein interactions. Oncogene. 2000; 19(50):5801-5809.

16. Kim YM, Ko CB, Park YP, Kim YJ and Paik SG. Octamer motif is required for the NF-kappaB-mediated induction of the inducible nitric oxide synthase gene expression in RAW 264.7 macrophages. Molecules and cells. 1999; 9(1):99109.

17. Jin $\mathrm{T}$ and $\mathrm{Li}$ H. Pou homeodomain protein OCT1 is implicated in the expression of the caudal-related homeobox gene Cdx-2. The Journal of biological chemistry. 2001; 276(18):14752-14758.

18. Wang L, Chen S, Xue M, Zhong J, Wang X, Gan L, Lam EK, Liu X, Zhang J, Zhou T, Yu J, Jin H and Si J. Homeobox D10 gene, a candidate tumor suppressor, is downregulated through promoter hypermethylation and associated with gastric carcinogenesis. Mol Med. 2012; 18:389-400.

19. Sasayama T, Nishihara M, Kondoh T, Hosoda K and Kohmura E. MicroRNA-10b is overexpressed in malignant glioma and associated with tumor invasive factors, UPAR and RhoC. International journal of cancer Journal international du cancer. 2009; 125(6):1407-1413.

20. Carrio M, Arderiu G, Myers C and Boudreau NJ. Homeobox D10 induces phenotypic reversion of breast tumor cells in a three-dimensional culture model. Cancer research. 2005; 65(16):7177-7185.

21. Terui K, Kitazawa J, Takahashi Y, Tohno C, Hayashi Y, Taketani T, Taki T and Ito E. Successful treatment of acute myelomonocytic leukaemia with NUP98-HOXD11 fusion transcripts and monitoring of minimal residual disease. British journal of haematology. 2003; 120(2):274-276.
22. Morgan R, Boxall A, Harrington KJ, Simpson GR, Gillett C, Michael A and Pandha HS. Targeting the HOX/ PBX dimer in breast cancer. Breast cancer research and treatment. 2012; 136(2):389-398.

23. Morgan R, Boxall A, Harrington KJ, Simpson GR, Michael A and Pandha HS. Targeting HOX transcription factors in prostate cancer. BMC urology. 2014; 14:17.

24. Morgan R, Pirard PM, Shears L, Sohal J, Pettengell R and Pandha HS. Antagonism of HOX/PBX dimer formation blocks the in vivo proliferation of melanoma. Cancer research. 2007; 67(12):5806-5813.

25. Morgan R, Plowright L, Harrington KJ, Michael A and Pandha HS. Targeting HOX and PBX transcription factors in ovarian cancer. BMC cancer. 2010; 10:89.

26. Thomas GJ, Poomsawat S, Lewis MP, Hart IR, Speight PM and Marshall JF. alpha $v$ beta 6 Integrin upregulates matrix metalloproteinase 9 and promotes migration of normal oral keratinocytes. J Invest Dermatol. 2001; 116(6):898-904.

27. Hosey AM, Gorski JJ, Murray MM, Quinn JE, Chung WY, Stewart GE, James CR, Farragher SM, Mulligan JM, Scott AN, Dervan PA, Johnston PG, Couch FJ, Daly PA, Kay E, McCann A, et al. Molecular basis for estrogen receptor alpha deficiency in BRCA1-linked breast cancer. J Natl Cancer Inst. 2007; 99(22):1683-1694. 